\title{
Ecodesenvolvimento, Desenvolvimento Sustentável e Economia Ecológica: em que sentido representam alternativas ao paradigma de desenvolvimento tradicional?
}

\section{Eco-development, Sustainable Development and Ecological Economics: In Which Sense do They Represent Alternatives to the Dominant Paradigm of Development?}

\author{
Brena Paula Magno FERNANDEZ*
}

\begin{abstract}
RESUMO
As razões pelas quais um determinado paradigma é escolhido em detrimento de outro não são apenas teóricas, mas também epistemológicas. Esse amálgama teórico-epistemológico, por sua vez, favorece um determinado tipo de propostas de desenvolvimento econômico. A economia neoclássica está estreitamente vinculada ao positivismo - lógico - (enquanto perspectiva epistemológica) e favorece a concepção de que o crescimento econômico virtualmente ilimitado seria condição necessária para o desenvolvimento econômico. A confiança de que o crescimento econômico medido em termos do aumento do PIB (per capita) seja uma boa medida de desenvolvimento reflete e exemplifica o domínio do mainstream em Economia em todos os três níveis: epistemológico/metodológico, teórico e pragmático/político. Quando confrontado com a necessidade de um Desenvolvimento Sustentável, por exemplo, ou com a persistência (ou mesmo o acirramento) do abismo econômico entre Norte e Sul, os limites do paradigma dominante se acentuam. Neste artigo, argumentamos que, a fim de suplantar este estado de coisas, as alternativas ao mainstream devem ser discutidas e articuladas em todos os três níveis supramencionados e que esse objetivo vem sendo perseguido pela proposta do Ecodesenvolvimento/Desenvolvimento Sustentável.
\end{abstract}

Palavras-chave: Ecodesenvolvimento; Desenvolvimento Sustentável; Economia Ecológica.

\section{ABSTRACT}

The reasons why scholars choose one paradigm to the detriment of another are not only scientific but also epistemological. This theoretical-epistemological amalgam, in its turn, provides a certain specific

\footnotetext{
"Economista, Pós-Doc em Filosofia da Ciência pela Universidade de São Paulo. Professora Adjunta do Departamento de Economia da Universidade Federal de Santa Catarina. Email: brena@cse.ufsc.br, brenafernandez@hotmail.com
} 
kind of economic development proposals. Neoclassical economics is closely connected with logical positivism (as an epistemological approach) and favors the conception that the virtually unlimited economic growth would be a necessary (and sufficient) condition to economic development. The strong reliance on economic growth in GDP-terms as an adequate indicator of economic development reflects and exemplifies the dominance of the mainstream in Economics at all three levels: methodological/ epistemological, theoretical and pragmatic/political. When faced with new challenges such as the need for a Sustainable Development, for instance, and the persistence (or even the increase) of the economic inequality between North and South, the shortcomings of the dominant paradigm become accentuated. In this paper we argue that, in order to overcome this state of affairs, alternatives to the mainstream ought to be discussed and articulated at all three levels mentioned above, and that this goal has been followed by the Eco-development/Sustainable Development proposal.

Key-words: Eco-development; Sustainable Development; Ecological Economics.

\section{Introdução}

A emergência do movimento ambientalista no final da década de 1960 e o choque do petróleo nos anos 1970 trouxeram para a ordem do dia os temas da depleção dos recursos naturais de uso comum, das opções alternativas de geração de energia e da pobreza em escala global. Esse cenário impulsionou a crítica aos modelos de desenvolvimento econômico até então vigentes, apontando para uma incompatibilidade congênita entre os processos convencionais de crescimento econômico e a garantia de sobrevivência da espécie humana no longo prazo.

$\mathrm{Na}$ época, a proposta de um novo estilo de desenvolvimento - o Ecodesenvolvimento - representava uma espécie de "terceira via", colocando-se como uma alternativa à bipolarização que o debate então assumira: por um lado, a proposta do "crescimento zero" e, por outro, as reivindicações desenvolvimentistas dos países do terceiro mundo: seu "direito ao crescimento".

Nas palavras de Maurice Strong, secretário-geral da Conferência das Nações Unidas sobre o Meio Ambiente e Desenvolvimento,

esse conceito normativo básico emergiu da Conferência de Estocolmo, em 1972. Designado à época como "abordagem do Ecodesenvolvimento", e posteriormente nomeado Desenvolvimento Sustentável, o conceito vem sendo continuamente aprimorado, e hoje possuímos uma compreensão mais acurada das complexas interações entre a humanidade e a biosfera (STRONG, apud SACHS, 1993, p. 7).

Por sua vez, o conceito de Desenvolvimento Sustentável emergiu no contexto da elaboração do Relatório Brundtland - Our Common Future -, de 1987, encomendado pela ONU, e, mais tarde, no transcurso da Eco-92, realizada no Rio de Janeiro.

Ignacy Sachs, diretor do Centro de Pesquisas do Brasil Contemporâneo, vinculado à Escola de Altos Estudos em Ciências Sociais de Paris, assim como Strong, emprega os conceitos de "Ecodesenvolvimento" e "Desenvolvimento Sustentável" como sinônimos, apontando cinco dimensões interconectadas de sustentabilidade: social (voltada para a redução da pobreza e para a organização social), econômica (relativa à manutenção da capacidade produtiva dos ecossistemas), ecológica (relacionada à preservação dos recursos naturais enquanto base da biodiversidade), espacial (voltada para uma configuração rural-urbana equilibrada) e cultural (referente ao respeito pelas especificidades culturais, identidades e tradições das comunidades locais) (SACHS, 1993, p. 24-27).

O surgimento dos conceitos de Ecodesenvolvimento e Desenvolvimento Sustentável está na raiz do campo teórico híbrido que veio a se constituir como a Economia Ecológica, de modo que esta passa a ser definida por alguns teóricos como a ciência da "gestão da sustentabilidade" (HAUWERMEIREN, 1998, p. 7).

\footnotetext{
${ }^{1}$ A ideia de "crescimento zero" foi popularizada pelo Relatório do Clube de Roma (MEADOWS et al., 1972) e para muitos significou um retorno aos temas malthusianos, onde o esgotamento dos recursos naturais e a poluição desempenhariam os mesmos papéis que a limitação das terras disponíveis e os rendimentos decrescentes na agricultura desempenharam para os clássicos.
} 
No presente trabalho, procuramos traçar um panorama histórico e conceitual do nascimento desses novos conceitos e propostas, alternativos àquilo que endossa a corrente teórica hegemônica. Como norte da discussão está o argumento de que as razões pelas quais um determinado paradigma é escolhido em detrimento de outro não são apenas teóricas, mas também epistemológicas. Esse amálgama teórico-epistemológico, por sua vez, favorece um determinado tipo de propostas num âmbito mais pragmático, de propostas políticas de desenvolvimento econômico.

A economia neoclássica está estreitamente vinculada ao positivismo - lógico - (enquanto perspectiva epistemológica) e favorece a concepção de que o crescimento econômico virtualmente ilimitado seria condição necessária (e, no limite, suficiente) para o desenvolvimento econômico. A confiança de que o crescimento econômico medido em termos do aumento do PIB (per capita) seja uma boa medida de desenvolvimento reflete e exemplifica o domínio do mainstream em Economia em todos os três níveis - epistemológico/metodológico, teórico e pragmático/político.

Entretanto, quando confrontados com novos desafios, como a necessidade de um Desenvolvimento Sustentável, por exemplo, ou a persistência (ou mesmo o acirramento) do abismo econômico entre Norte e Sul, os limites do paradigma dominante se acentuam. Nosso intuito será argumentar que, a fim de suplantar este estado de coisas, as alternativas ao mainstream devem ser discutidas e articuladas em todos os três níveis mencionados.

A fim de introduzir estas questões, acreditamos que seja bastante útil recuperar, em linhas gerais, a trajetória percorrida pela mais antiga das ciências sociais - a Economia -, a partir do momento em que esta se estabelece como disciplina autônoma, até os dias atuais (seção 1), enfatizando as questões que nos interessam particularmente aqui, como é o caso do tratamento da natureza pela escola neoclássica (item 1.1), e dos valores implícitos que, segundo se critica, permanecem, a despeito da busca pela neutralidade axiológica, que é uma das marcas da visão positivista do mundo econômico (item 1.2). Logo em seguida, apresentamos a perspectiva teórica da Economia Ecológica (seção 2) e procuramos explicitar de que forma as propostas do Ecodesenvolvimento e do Desenvolvimento Sustentável a ela se coadunam (seção 3). Esse tipo de abordagem com- parativa permite-nos destacar a fecundidade das propostas alternativas aqui apresentadas.

\section{O processo de cientifização da Economia- Positivismo, objetividade e neutralidade axiológica}

Se analisada a partir de uma perspectiva histórica ampla, a Economia integrou-se a um projeto comum, que norteou o desenvolvimento das mais variadas disciplinas que aspiravam ao status de ciência. Tendo se instituído como disciplina independente no último quartel do século XVIII, o desenvolvimento da Economia foi fortemente norteado pela concepção de cientificidade instaurada na modernidade, cujo ideal incluía, como parte do processo de autonomização das esferas do saber, um movimento em direção às explicações de caráter formal, mecânico e matemático. Em última análise, esse movimento consistia na busca de causas e de leis para os fenômenos econômicos, ou ainda na busca de suas condições de repetibilidade ${ }^{2}$.

Entretanto, o passo definitivo em direção à formalização e à matematização na Economia foi dado no século XIX, por volta de 1870 , pelos protagonistas do movimento que viria a tornar-se conhecido como "revolução marginalista". A abordagem teórica neoclássica, então inaugurada, promoveu uma verdadeira revolução metodológica no âmbito da disciplina, uma vez que não apenas introduziu novas técnicas matemáticas (em especial o cálculo diferencial) e ampliou essa linguagem na teorização econômica, como também instituiu uma separação bastante nítida entre ciência e arte. $\mathrm{O}$ estudo da Economia passou a dividir-se entre uma abordagem "positiva" - científica e matemática -, por um lado, e uma abordagem "normativa" - a arte das aplicações de política econômica, por outro (KEYNES, 1890).

Naquela ocasião, um dos objetivos centrais era o de expurgar as influências valorativas do âmbito da Economia positiva e em seu lugar fazer passar a vigorar o modelo científico, a-histórico - formal/matemático - de investigação da realidade. E isso a ponto de Jevons ter apresentado, em 1871, seu projeto para desenvolver a Economia como a "mecânica da utilidade e do interesse-próprio"3. O mesmo ideal teria levado Comte a chamar a Sociologia de "Física

\footnotetext{
${ }^{2}$ Guardadas as devidas proporções, a publicação da obra seminal de Adam Smith, The Wealth of Nations, em 1776, foi, para a Economia, um marco comparável àquilo que representou a publicação dos Principia, na Física Clássica: o momento em que a disciplina se estabelece como autônoma.

${ }^{3}$ JEVONS, W. S. (1871). Citado em Georgescu-Roegen, N. (1979, p. 118).
} 
Social" e Walras a afirmar, em 1874, nos seus Elementos de economia política pura, que "o sistema econômico revela-se em todo o seu esplendor e complexidade, um sistema simultaneamente vasto e simples que se assemelha em beleza pura ao universo astronômico"4.

Este movimento só pôde ocorrer na medida em que incorporou alguns dos preceitos epistemológicas fundamentais do Positivismo para as ciências sociais, dentre os quais podemos destacar [as ideias de que]:

(i) a sociedade é regida por leis naturais, eternas, imutáveis, independentes da vontade e da ação humana. E na vida social reina uma harmonia natural;

(ii) a sociedade pode ser epistemologicamente assimilada pela natureza, sendo estudada pelos mesmos métodos e processos das ciências naturais;

(iii) as ciências naturais e sociais devem limitar-se às explicações causais dos fenômenos de forma objetiva, neutra, livre de juízos de valores e ideologias, livre de noções prévias e preconceitos ${ }^{5}$.

Apesar de bastante consolidada e ainda dominante, essa concepção geral de ciência vem sendo confrontada com diferentes tipos de críticas ao longo das últimas quatro décadas, pelo menos. Em comum, essas críticas pós-positivistas - sejam elas ambientalistas, kuhnianas, feministas ou dos filósofos que reivindicam falar em nome de segmentos oprimidos do terceiro mundo - compartilham justamente a rejeição da tese de que os valores não exerçam qualquer papel significativo nas ciências (puras ou aplicadas). (cf. LACEY, 1998, 1999; LONGINO, 1990).

Se o argumento de que não é possível a configuração de uma estrutura teórica completamente isenta de orientações valorativas vale para o âmbito da teoria pura ou positiva, com mais razão ainda deve valer para o caso de áreas mais aplicadas, como é o caso do campo de estudos que se convencionou chamar de desenvolvimento econômico, ou ainda sua variante que incorpora o tratamento da questão ambiental - o desenvolvimento sustentável.

\subsection{O tratamento da natureza na economia ortodoxa}

Até a década de 1970, as teorias de desenvolvimento econômico concebidas para interpretar o capitalismo não levavam em conta os componentes ambientais - fossem eles renováveis ou não -, como o esgotamento dos recursos naturais, a poluição ou a destruição dos ecossistemas. A desconsideração desses aspectos deve-se, sobretudo, ao fato de que, até aquele momento, a pressão das atividades humanas sobre o meio ainda não havia atingido um nível crítico. Foi, portanto, a partir dos anos 1970, quando as questões do meio ambiente e dos recursos naturais passam a configurar um problema para a humanidade, que elas começam a ser entendidas e tratadas enquanto tais no âmbito das teorias econômicas.

Segundo Faucheux e Nöel (1995, p. 25-28), foram quatro os grandes paradigmas que se firmaram, cada qual representando uma atitude no que concerne ao posicionamento da atividade econômica frente à natureza: uma primeira abordagem, preservacionista ao extremo, cujo foco concentra-se na defesa da preservação total da biosfera - a chamada Deep Ecology (que não deve ser confundida com a ciência da Ecologia). Esse movimento é muitas vezes acusado de reducionismo, uma vez que tende a abandonar todas as considerações econômicas e sociais, desembocando em conclusões e preceitos extremamente rígidos - "biocentrados" - de direitos éticos equivalentes entre seres humanos e não humanos, por exemplo.

Uma segunda corrente é representada pelo modelo neoclássico, que, como analisamos acima, ao fundamentar-se na mecânica clássica, assume um mundo que se deixa explicar única e exaustivamente por suas dimensões quantificáveis. Como as modificações qualitativas ficam, segundo essa abordagem, excluídas, esse modelo abre as portas para uma intervenção sem limites do homem sobre o universo físico.

O terceiro paradigma, desenvolvido a partir da introdução do conceito de entropia na análise do fenômeno econômico, concebe os problemas ambientais como barreiras intransponíveis, defendendo uma atitude francamente conservacionista: o crescimento zero ou estado estacionário.

Já a quarta vertente - Ecodesenvolvimento ou Desenvolvimento Sustentável - representa uma posição de compromisso valorativo - ético e ecológico - entre a economia, por um lado, e os recursos naturais e o meio ambiente, por outro. "Centrado mais na biologia do que na física, este paradigma irá insistir na instabilidade da vida face ao mundo físico, na crescente complexificação do vivo e na necessidade de organizar a coevolução" (FAUCHEUX; NÖEL, 1995, p. 28).

\footnotetext{
${ }^{4}$ WALRAS, L. (1874, p. 25).

${ }^{5}$ LÖWY, M., 1998, p. 17 e s.
} 
Nesse ponto da discussão, concentramo-nos na segunda corrente - Escola Ambiental Neoclássica - a qual se constitui, hoje, no pensamento dominante no mundo capitalista, enquanto que a quarta posição - Ecodesenvolvimento/Desenvolvimento Sustentável - será tratada com maiores detalhes no item 4 .

Inicialmente, os recursos naturais sequer apareciam nas representações analíticas do mainstream neoclássico: na representação econômica especificada pela função de produção, entravam apenas capital e trabalho - a economia funcionava teoricamente sem recursos naturais (implícita nessa representação está a concepção, herdada dos clássicos, de infinitude desses recursos). Foi, desta forma, somente com o tempo e em resposta à crise desencadeada que alguns instrumentos da ortodoxia neoclássica foram usados para incluir os recursos naturais como um dos fatores na representação da função de produção $(\mathrm{Y}=\mathrm{f}(\mathrm{K}, \mathrm{L}, \mathrm{R})$, onde $\mathrm{Y}=$ Produção, $\mathrm{K}=$ capital, $\mathrm{L}=$ trabalho e $\mathrm{R}=$ recursos naturais) (ROMEIRO, 2001).

A abordagem padrão da Economia dos recursos naturais e do meio ambiente - escola ambiental neoclássica baseia-se na ideia da internalização das externalidades (i.e., no pressuposto de que todo bem ou recurso ambiental não incluído no mercado pode receber uma valoração monetária adequada). Esse artifício conseguiria reverter a tendência à exaustão dos recursos naturais, bem como a degradação ambiental total, que, segundo essa corrente, ocorre devido à "falha do mercado" em alocar eficientemente os recursos.

O embrião desses argumentos foi um artigo seminal de Ronald Coase - "The Problem of Social Cost" -, publicado em 1960 (que se tornou conhecido como "Teorema de Coase"), no qual este autor contrapunha-se à solução pigouniana em relação aos conflitos originados pelas externalidades negativas. Enquanto Pigou defendia o princípio do poluidor pagador, Coase afirmava que em uma economia na qual todos os ativos pertencessem a alguém não haveria a necessidade de regulação por parte do governo, pois isto seria feito pelo próprio mercado.

Significa dizer que a questão fundamental passa a ser como imputar valor econômico (monetário) àquilo que o mercado normalmente não considera como possuindo valor (e, consequentemente, que não se expressa através de preços), ou aos bens e recursos que se encontram subvalorados. Ou seja, através da solução pela negociação via mercado, o pagamento dos prejuízos causados concede o direito à continuidade da geração das externalidades.
Os limites ambientais ao crescimento econômico poderiam ser expandidos indefinidamente, de acordo com este enfoque, principalmente em função dos mecanismos de mercado, tanto no que toca aos bens ambientais que já são transacionados (recursos naturais, energéticos ou não) quanto no caso dos chamados bens públicos. Nesse último caso, preços poderiam e deveriam ser imputados tanto àqueles bens que atualmente não possuem valoração alguma (como no caso da utilização do ar, por exemplo), como àqueles que não possuem valoração adequada (água, capacidade de assimilação de detritos).

A escassez crescente de um dado bem ou recurso natural traduzir-se-ia na elevação de seu preço e na imediata introdução de alguma inovação tecnológica que permitisse poupá-lo e/ou substituí-lo por outro recurso mais abundante e, consequentemente, mais barato. Já no caso dos recursos não transacionados, falha esse mecanismo e torna-se necessária uma intervenção governamental no sentido de imputar valores (taxações, multas) a eles. Convém salientar que as técnicas para definir valorações aos bens e serviços ambientais propostas pelos economistas neoclássicos (como, por exemplo, o princípio do poluidor-pagador) são baseadas no princípio da negociação, que, para essa corrente, rege o mercado.

O otimismo tecnológico, intrínseco a essa representação, pressupõe como condição a possibilidade de substituição perfeita dos fatores de produção em função dos preços. Dito de outro modo, os limites impostos pelo esgotamento dos recursos naturais poderiam ser indefinidamente superados pelo progresso técnico, uma vez que aqueles, à medida que fossem se tornando escassos, poderiam ser substituídos, seja por outra fonte de recursos, seja por capital, seja por trabalho.

Essa atitude, dominada pela noção de eficiência econômica do mercado, deixa a cargo deste também o papel de regulador na exploração dos recursos naturais. Com efeito, "tudo se passa como se o sistema econômico fosse capaz de se mover suavemente de uma base de recursos para outra à medida que cada uma é esgotada, sendo o progresso científico e tecnológico a variável chave para garantir que esse processo de substituição não limite o crescimento econômico a longo prazo" (ROMEIRO, 2001, p. 10). Essa visão deixa claramente o caminho aberto à exploração indefinida dos recursos naturais e do meio ambiente. 


\subsection{Os valores subjacentes ao tratamento ortodoxo da Economia}

Ante o exposto, em que pese a reivindicação, por parte da tradição, da suposta neutralidade axiológica da Economia (enquanto ciência positiva), segundo se critica, a concepção da análise econômica atualmente dominante pressupõe implicitamente que, "nenhum outro objetivo é concebível, exceto o da maximização da utilidade ou do lucro, numa perspectiva microeconômica, e o do crescimento econômico, numa abordagem macroeconômica" (FAUCHEUX; NÖEL, 1995, p. 52).

O pano de fundo valorativo da abordagem neoclássica consistiria exatamente em favorecer o crescimento econômico, supondo-se que a maximização deste aumentasse, a reboque, tanto a satisfação do consumidor, no nível individual, quanto o bem-estar humano, numa perspectiva global. Uma vez que a maximização da utilidade total líquida estaria, através dos mecanismos de mercado, garantida, o objetivo de maximização do bem-estar seria, da mesma forma, cumprido, não cabendo à teoria qualquer explicação (ou responsabilidade ética) com relação à distribuição resultante. Com efeito, a partir desse enfoque, qualquer consideração de equidade (inclusive intrageracional) está, de antemão, excluída.

A ética ligada à teoria dominante dos recursos naturais e do meio ambiente revela-se, ao invés disso, fundamentalmente antropocêntrica, utilitarista e "presentista". Por um lado, o meio ambiente é considerado como um conjunto de bens disponíveis para sua utilização pelo homem - os recursos naturais apenas possuem algum valor em função de sua utilidade, direta ou indireta, para a humanidade. Por essa razão, a abordagem econômica ambiental tradicional mostra-se simultaneamente utilitarista e antropocêntrica.

Por outro lado, tendo em vista que, segundo a teoria, gerações futuras supostamente encontrar-se-ão em um nível de riqueza superior, se comparadas aos seus antepassados, consequentemente serão também mais capazes de responder à deterioração ambiental que herdarão. Desta forma, a geração presente fica igualmente eximida de quaisquer compromissos ou obrigações para com as gerações vindouras (ou seja, de toda exigência de equidade intergeracional).

Como abordagem teórica alternativa à teoria neoclássica, dentre outras correntes heterodoxas, surge a economia ecológica, com o intuito justamente de tentar oferecer um tratamento da questão econômica que englobasse uma perspectiva mais ampla da realidade econômica e que propusesse respostas mais adequadas aos problemas acima apresentados.

\section{O que é Economia Ecológica?}

A Economia Ecológica é um dos mais recentes programas de pesquisa em ciência econômica. Apesar de suas motivações remontarem à crítica ambiental de fins da década de 1960, essa abordagem só veio a se consolidar como corrente no final da década de 1980, com a fundação da International Society for Ecological Economics (ISEE) e a criação da revista Ecological Economics, em 1988 e 1989, respectivamente.

Esse programa de pesquisa emergente passa a propor uma nova interpretação dos laços entre homem (sistema econômico) e natureza (meio ambiente). Sua crítica ao processo de crescimento econômico atual toma por base os princípios, conceitos e ferramentas biofísicos-ecológicos: se por um lado o funcionamento do sistema socioeconômico baseia-se e depende dos sistemas ecológicos, por outro, estes últimos interferem e transformam seu próprio funcionamento.

A partir do reconhecimento da necessidade de uma maior integração entre o sistema econômico e o ambiente natural, no qual aquele se insere, a Economia Ecológica defende que a atual problemática ambiental e as perspectivas de um Desenvolvimento Sustentável não podem ser devidamente compreendidas apenas nos marcos da Economia ou da Ecologia convencionais. Propõe, portanto, uma análise baseada na relação de interdependência dos dois sistemas.

Por ser um campo de pesquisa incipiente e ainda extremamente plural, a Economia Ecológica integra contribuições bastante heterogêneas, que recorrem ora a conceitos e instrumentos da Ecologia, ora a conceitos e instrumentos da abordagem econômica tradicional, sempre que uns ou outros se fazem necessários. Porém, permanece como substrato comum o reconhecimento da fundamental importância dos princípios biofísicos (em particular a Lei da Conservação - Primeira Lei da Termodinâmica - e a Lei da Entropia - Segunda Lei da Termodinâmica $)^{6}$ para a

\footnotetext{
${ }^{6}$ A partir do trabalho seminal de Georgescu-Roegen (1971).
} 
compreensão das inter-relações e da perspectiva de gestão de sustentabilidade dos sistemas socioambientais.

O conceito de sustentabilidade delineia-se com base na especificação das diversas funções ecológicas envolvidas no processo, em particular a capacidade do meio ambiente de suprir o funcionamento dos sistemas produtivos com recursos naturais e, no sentido inverso, sua aptidão para absorver os resíduos correspondentes. Dessa forma, o objetivo central da pesquisa seria estabelecer em que medida as restrições ambientais podem ou não representar limites mais ou menos drásticos para o crescimento econômico no longo prazo.

Acerca dessa questão, a Economia Ecológica não adota nenhuma postura a priori, procurando resguardar um "ceticismo cauteloso" ou "prudente". Assim, não compartilha o ceticismo alarmista e pessimista, típico do posicionamento adotado pelos proponentes do "crescimento zero", por exemplo, entendendo os limites ecológicos como absolutos e intransponíveis. Tampouco assume o "otimismo tecnológico" adotado pela corrente hegemônica, segundo o qual as restrições ambientais são vistas como um problema menor, que sempre pode ser superado pela tecnologia. Sua posição consiste em reconhecer que o progresso tecnológico efetivamente se dá, promovendo constantemente a superação de limites circunstanciais, seja através do aumento da eficiência no uso dos recursos, seja pela substituição de recursos exauríveis por outros, renováveis. Reconhece, finalmente, que essa dinâmica esbarra em restrições biofísicas insuperáveis.

Seus adeptos enfatizam a utilização dos recursos renováveis a uma taxa que não exceda seu ritmo de regeneração e o manejo prudente dos recursos não renováveis, sempre a uma taxa não superior à sua taxa de substituição por recursos renováveis. Nesse sentido, a quantidade de resíduos gerada não deve extrapolar a capacidade de suporte do meio ambiente, conservando-se ao mesmo tempo a diversidade biológica (CONSTANZA, 1991).
Esta visão de mundo, diferentemente da anterior, entende a relação entre o meio ambiente e a economia como uma relação em que a economia constitui um subsistema do meio ambiente, interagindo e dependendo dele intensamente em dois sentidos: como fonte de matérias-primas (insumos) ou como depósito para os resíduos (DALY, 1999). Esta visão da economia como um subsistema do meio ambiente constitui a pedra angular nas formulações da economia ecológica, sobretudo, por ser ponto de partida e base para a crítica à economia convencional, que considera a economia um sistema fechado. Outro fundamento da economia ecológica é seu comprometimento explícito com um posicionamento valorativo. Esse ponto consiste no reconhecimento da necessidade de um posicionamento de defesa da equidade social, tanto com as gerações atuais como com as futuras ${ }^{7}$. Os conceitos de Desenvolvimento Sustentável e de Ecodesenvolvimento estão solidamente apoiados nesses princípios, inexistentes na economia ambiental tradicional.

\section{Ecodesenvolvimento/Desenvolvimento Sustentável ${ }^{8}$ : em que sentido representam alternativas ao modelo tradicional de desenvolvimento econômico?}

Em primeiro lugar, o modelo tradicional presume que o uso do método formal matemático garanta a objetividade dos resultados alcançados pela pureza lógica de suas provas e através de sua generalidade, supostamente livre de valores. Todavia, uma crítica recorrente não só da corrente de pensamento aqui tratada, como também por parte de outras correntes heterodoxas, é a de que, em sua busca pela objetividade, a teoria econômica padrão teria limitado o domínio da investigação apenas àqueles aspectos da realidade que são passíveis de serem formalmente modelados, de modo que são as possibilidades da metodologia que

\footnotetext{
${ }^{7}$ Este ponto será desenvolvido mais detalhadamente abaixo, no item 3.1.

${ }^{8}$ Tomamos aqui os conceitos de Ecodesenvolvimento e de Desenvolvimento Sustentável como sinônimos, seguindo Sachs (1981, 1986, 1993). Esta é uma simplificação útil por uma questão de limitação de espaço e de escopo do presente trabalho. Entretanto, ela necessariamente deixará de fora da discussão uma série de aspectos de não menor relevância. Diversos autores vinculados a uma vertente mais crítica deste ponto de vista argumentam, por exemplo, que o conceito de "Desenvolvimento Sustentável" acabou por constituir-se essencialmente num subterfúgio (ou num artifício) para a perpetuação da lógica estrutural da dinâmica da globalização "perversa", porém travestido de uma nova linguagem. Esse seria um dos motivos pelos quais vem se tornando um lugar-comum na linguagem dos grandes conglomerados transnacionais e da mídia o apelo retórico à busca por um "Desenvolvimento Sustentável”. Nesta linha crítica, Martínez Alier (1998, p. 360361), por exemplo, (ironicamente) denomina a proposta do Desenvolvimento Sustentável de "Ecotecnocracia" e de "Capitalismo esverdeado". No limite, segundo essa vertente, haveria uma total impossibilidade de se atingir a "sustentabilidade" dentro da lógica capitalista de apropriação degenerativa dos recursos naturais. Este é o argumento de Montibeller-Filho (2001), como o provocativo título de e sua obra - O mito de desenvolvimento sustentável - já antecipa.
} 
definem o objeto a ser estudado, e não o contrário, como seria de se esperar.

Essa definição de Economia, que se dá, portanto, preferencialmente através de um método restritivo, ao invés de se pautar pela especificação de seu objeto de investigação, tem causado alguns atropelos, sendo talvez o mais grave deles a total perda de interesse pela resolução teórica dos problemas econômicos (práticos) mais candentes que afligem a humanidade (como os efeitos perversos da globalização e do livre trânsito de capitais, a pobreza, a fome, as crises social, política e energética mundiais, a estagnação dos países do hemisfério sul e, obviamente, o virtual esgotamento dos recursos naturais) ${ }^{9}$.

Por outro lado, o reducionismo científico tem funcionado como uma estratégia eficiente para impedir o desenvolvimento de abordagens alternativas. Ao buscar assegurar as credenciais epistêmicas da Economia através de sua adesão ao método científico tradicional, a corrente teórica hegemônica passou a apresentar-se como a única forma possível de conhecimento racional, no limite interditando o avanço de correntes teóricas alternativas para a explicação do fenômeno econômico.

Essa exclusão concretiza-se, em primeiro lugar, através da eliminação de cadeiras de história do pensamento econômico (onde o pensamento dominante poderia ser confrontado com outras alternativas teóricas, tanto do passado quanto atuais) do currículo mínimo para a formação de economistas nas instituições de maior prestígio mundial. E depois sob a forma de dificuldades na obtenção de financiamentos para pesquisas, assim como nos problemas encontrados para a publicação, em bons periódicos, dos trabalhos cujos focos de interesse não se coadunam com o arcabouço analítico - métodos, axiomas e conceitos - do mainstream $^{10}$.

A contraproposta apresentada pelo Ecodesenvolvimento/Desenvolvimento Sustentável insiste, de início, que se invertam os termos e o objeto de estudo da Economia seja claramente definido antes da deliberação sobre qual (ou quais) método(s) adotar. Depois, propõe uma redefinição do próprio objeto: ao invés da definição baseada no princípio das trocas e na maximização de ganhos individuais, que a Economia passe a ser definida como o estudo da provisão social. Remonta a Aristóteles a origem dessa ideia ${ }^{11}$. Em sua célebre distinção entre economia (oikonomia, em grego) e crematística, ele identifica a primeira com a provisão dos bens para o sustento do homem, da casa e da polis, enquanto à crematística é delegado o estudo da formação dos preços no mercado.

Implícita nesta definição de economia como provisão social está a ideia de que a atividade econômica é, antes de tudo, a maneira através da qual os indivíduos se organizam coletivamente, produzem e distribuem os meios necessários para a sua sobrevivência. $\mathrm{O}$ foco aqui recai sobre a produção e a geração de bens, mercadorias e serviços necessários para a manutenção da vida humana.

Vejamos: em primeiro lugar, a economia entendida como provisão social de bens e serviços para a humanidade enfatiza uma análise das atividades econômicas enquanto um processo social interdependente. Enquanto processo, a economia está sujeita a contínuas transformações e não existe nenhum indício de que tenda a algum tipo de "equilíbrio" (mesmo que dinâmico). Depois, como está imbricada no contexto ecológico, social, cultural e político de determinado período histórico, a economia é afetada pela dinâmica de todos estes elementos da sociedade na qual se insere e afetará essa dinâmica em contrapartida. Entender a atividade econômica sob esse prisma teórico ilumina a maneira como a sociedade produz, se reproduz e se auto-organiza. Essa organização é fruto de um conjunto de ações sociais e não do simples somatório de escolhas individuais independentes. Quanto à repartição de seus resultados materiais, ela é produto de divisão social e não da maximização da "utilidade total líquida".

Numa palavra, essa redefinição visa a reinserir a Economia no âmbito socioambiental do qual faz parte e, com isso, recuperar o ideal de ciência novamente voltado para

\footnotetext{
${ }^{9}$ Esse distanciamento da realidade chegou a tal ponto que deu margem, em 2001, a um movimento que identifica a Economia contemporânea ao autismo - patologia caracterizada pelo desligamento do indivíduo por ela acometido do mundo exterior, e pela criação mental de um mundo próprio. A reivindicação desse movimento, que congrega as mais diversas linhas heterodoxas, é, obviamente, uma situação em que a Economia novamente se revincule à realidade - uma Economia Pós-Autista (Post-Autistic Economics) -, com todas as implicações metodológicas e epistemológicas que a tarefa exige. Todo seu histórico, bem como os artigos da revista então criada (Post-Autistic Economics Review), podem ser acessados através do link www.paecon.net. Para uma crítica pós-autista a partir da abordagem da economia ecológica, ver Constanza, 2003.

${ }^{10} \mathrm{O}$ leitor não familiarizado com o mainstream em Economia pode verificar esse fato folheando alguns de seus mais prestigiosos periódicos (como, por exemplo, o American Economic Review, o Econometrica e o Journal of Political Economy). Nessas revistas, o grau de concordância sobre o núcleo teórico duro da disciplina pode surpreender outros cientistas sociais. Ademais, escolas rivais jamais são sequer mencionadas.

${ }^{11}$ Ver particularmente o Livro I, de Política (ARISTÓTELES, 1983).
} 
atender aos objetivos humanos (presente e futuros), como a disciplina foi originariamente desenvolvida para fazer, e não aos objetivos do mercado - como tem ocorrido cada vez mais intensamente nas últimas décadas. A redefinição do objeto de estudo da Economia, entretanto, é apenas a primeira parte do projeto. A segunda levanta questões vitais em relação à metodologia tradicional que é usada para explicar o mundo econômico.

Uma vez redefinido o objeto da Economia como o estudo da provisão social (necessariamente inserida num contexto natural - biofísico - que impossibilita o aumento indefinido da produção de bens), tem-se como consequência uma redefinição daquilo que deva ser entendido como desenvolvimento, agora sobre novas bases: "desenvolvimento sustentável" passa a consistir numa situação de melhora na qualidade de vida de cada cidadão - do presente e do futuro - com um nível de uso dos ecossistemas que não exceda sua capacidade regenerativa e assimiladora dos rejeitos do ambiente natural.

Um ponto central a ser aqui destacado é que a base do enfoque alternativo aqui tratado remete ao pensamento interdisciplinar, procurando incluir todas as inter-relações constitutivas do sistema humano com a natureza (subsistemas ambiental, econômico, político e cultural).

Com relação à questão metodológica, podemos afirmar que é para uma concepção mais ampla da racionalidade científica (no âmbito socioeconômico) que se dirigem suas propostas - tanto em relação à incorporação dos limites biofísicos da natureza no tratamento da questão do desenvolvimento econômico sustentável, como em relação à perspectiva interdisciplinar que normalmente deve ser buscada. Essa concepção "ampliada" de racionalidade científica, por sua vez, remete a uma concepção de ciência reformulada no sentido de incluir estruturas narrativas, como é o caso dos trabalhos dos autores aqui tratados. Sob este prisma, a diferença entre a concepção neoclássica e as concepções heterodoxas não mais se manifestariam na oposição entre "fazer ciência" e "não fazer ciência", mas sim em fazer dois tipos diferentes de ciência - ambas podendo ser boas, rigorosas, adequadas, ou não. Nesse novo quadro, o critério de cientificidade que deve ser levado em conta é a adequação empírica, abrindo-se mão da premência da formalização como critério último de rigor e objetividade.

Também se contrapondo à abordagem tradicional, os defensores das propostas do Ecodesenvolvimento e do Desenvolvimento Sustentável entendem ser insatisfatório o tratamento das questões ambientais mediante o recurso da "internalização" (monetária) de "externalidades" (custos externos). Como assinalamos anteriormente, de acordo com esse recurso, os problemas ambientais seriam custos sociais decorrentes de "falhas do mercado", que não conseguiria medir (valorar, precificar) adequadamente as preferências subjetivas dos agentes em relação aos bens e recursos ambientais. Ocorre que, mesmo que as "externalidades", por hipótese, pudessem ser adequadamente "internalizadas", nada garante que a otimização econômica daí decorrente viesse a promover uma utilização sustentável dos recursos naturais no longo prazo. Significa afirmar que "otimização" ou "maximização" econômicas não são equivalentes à "sustentabilidade ambiental". A menos que nos fosse dado conhecer toda a complexa gama de relações entre homem e natureza, assim como toda a rede de desejos, aspirações e valores, tanto da sociedade atual, quanto das gerações futuras, esse projeto afigura-se inviável.

As propostas do Ecodesenvolvimento e do Desenvolvimento Sustentável entendem que as interações entre o sistema social, o meio ambiente e o sistema econômico são regidas por relações fundamentais de valores, sendo que estes não podem ser apreendidos pelo artifício da imputação de preços de mercado às preferências dos indivíduos. Dentre esses valores encontra-se a importância da manutenção da biodiversidade, não entendida aqui em seu sentido antropocêntrico e utilitarista, direto ou indireto, na medida em que serve à utilização (atual ou potencial) pelo homem, mas sim em consonância com os princípios ecológicos mais fundamentais, de manutenção da resiliência ecossistêmica em escala global.

Além disso, essas correntes consideram como imprescindível a incorporação do tratamento da questão valorativa da equidade, em busca da superação progressiva das assimetrias sociais - também em escala global. Estas são, como vimos anteriormente, acarretadas e intensificadas pela ideologia economicista hegemônica. São também teoricamente legitimadas pelo tratamento standard (objetivo e "neutro") da Economia. Assim, podemos dizer que, segundo essa perspectiva, do mesmo modo que "maximização" econômica não pode significar "sustentablidade ambiental", tampouco "crescimento econômico" é sinônimo de "desenvolvimento social", em sentido amplo.

O crescimento econômico "a qualquer custo" não constitui uma panaceia, como pensaram os primeiros economistas. De fato, como enfatiza Cavalcanti: 
o crescimento pressupõe aumento físico, alargamento das dimensões da economia, enquanto desenvolvimento, no seu sentido mais rigoroso, não quer necessariamente significar crescimento. Pode ser uma transformação estrutural da economia, uma realização do potencial de atendimento das necessidades básicas, uma mudança qualitativa (para melhor, presumivelmente) (1997, p. $63)$.

E continua, na mesma página, referindo-se ao projeto do Ecodesenvolvimento: "[este] significa abandonar os supostos discutíveis do crescimento sem limites, tão caro à tradição de pensar dos economistas [neoclássicos] (e daqueles que os consultam)".

A confusão entre crescimento econômico e desenvolvimento social baseia-se no pressuposto de que a satisfação das necessidades humanas seria tanto maior quanto mais elevado fosse o nível do produto nacional bruto. Essa visão da Economia corresponde à ideologia dominante na época em que foi teorizada (final do século XVIII e início do século XIX), na Europa, onde as necessidades básicas dos indivíduos mal eram satisfeitas. Naquele estágio do desenvolvimento econômico, os níveis de vida da população como um todo se mantinham muito próximos ao mínimo vital. Fazia sentido, portanto, a afirmação de que todo acréscimo na produção de bens gerava um nível superior de bem-estar (PASSET, 2000, p. 37).

Ao mesmo tempo, a questão da natureza foi desconsiderada pelos primeiros economistas. Isto porque as atividades produtivas ainda não implicavam em riscos mais ou menos irreversíveis à biosfera, colocando em questão as regulações que governam sua reprodução e suas grandes funções, como acontece hoje com o controle térmico do planeta, por exemplo.

Apesar das evidências acumuladas sobre as mudanças ambientais globais, as escolas modernas de economia persistem em isolar a esfera econômica das esferas cultural e biológica. A ortodoxia permanece no âmbito de uma Economia unidimensional, desligada de seu contexto e que hipertrofia a dimensão quantitativa.

Parece assim inescapável a necessidade de abordagens alternativas, capazes de tratar as interdependências de um mundo que vem se complexificando aceleradamente. Quando se percebe que para produzir crescimento destrói-se o meio ambiente e acentuam-se as desigualdades sociais, já não se pode mais isolar o setor econômico. Torna-se necessário ressituar a atividade econômica na esfera humana, especialmente no campo dos valores. Uma Economia ligada às outras esferas obriga que se coloque a questão do humano, do social, da ética e da natureza. Voltamos à questão dos valores e sua centralidade nessa discussão necessita, portanto, de um exame mais detido.

\subsection{O papel dos valores nas abordagens do Ecodesenvolvimento e do Desenvolvimento Sustentável}

Afirmam os críticos que não existiria qualquer teoria econômica, mesmo as mais ortodoxas, que propusessem que a Economia fosse outra coisa além de uma atividade de transformação da natureza voltada para a satisfação das necessidades humanas. A Economia não teria outra razão de ser: os problemas ambientais, assim como os humanos e sociais atuais, decorreriam do fato da atividade econômica ter se tornado um fim em si mesma, ao invés de um meio a serviço das finalidades humanas. Um dos equívocos mais graves que contribuíram para essa distorção teria sido a confusão entre dois conceitos distintos: crescimento e desenvolvimento, um quantitativo e outro qualitativo (PASSET, 2000, p. 36-37).

A extensão das consequências que se relacionam aos empreendimentos humanos (da biosfera às gerações futuras) trouxeram novamente para o primeiro plano a questão da responsabilidade - e, portanto, da ética - para o campo da Economia. "Trata-se de gerir a natureza de forma a assegurar aos homens de nossa geração e a todas as gerações futuras a possibilidade de se desenvolver" (SACHS, 1981, p. 14). Nesse ponto, quando é chegado o momento em que as questões econômicas não podem mais isolar-se da questão dos valores, o argumento segundo o qual a Economia positiva seria neutra, objetiva e universal, porquanto a única científica, não resiste. "Em nome de que privar-se hoje para gerações futuras que nem sequer conheceremos?" Atualmente, não existe resposta no arcabouço teórico da Economia neoclássica para uma pergunta como esta.

Trata-se aqui, do "princípio responsabilidade" (Das Prinzip Verantwortung - JONAS, 1979), ou seja: nosso dever e responsabilidade com relação à natureza, à vida e ao futuro das próximas gerações sobre a Terra. Esta responsabilidade não se restringe à esfera do sujeito individual; seu verdadeiro destinatário é a práxis coletiva. A preocupação primordial de Jonas diz respeito aos efeitos remotos, cumulativos e irreversíveis das ações da sociedade 
tecno-científica-industrial sobre a natureza e sobre o próprio homem. O novo imperativo ético proposto por Jonas ("Age de tal maneira que os efeitos de tua ação sejam compatíveis com a permanência de autêntica vida humana sobre a Terra"), também conhecido como imperativo ecológico, não se dirige - como o imperativo categórico de Kant o fizera - ao comportamento do indivíduo privado, mas sim ao agir coletivo. Sua destinação não é, portanto, a esfera próxima das relações entre singulares, mas a do domínio da política pública.

Isso acarreta duas implicações: em primeiro lugar, a equidade intergeracional encontra-se aqui no centro das preocupações da economia, com respeito à sustentabilidade, designando claramente as paradas necessárias para a coexistência socioeconômica e ecológica através do tempo. E, depois, acarreta ainda a indicação da superioridade da esfera pública - política - (no que toca às finalidades e objetivos) sobre a função econômica (PASSET, 2001).

Nesse tecido cultural alternativo, o interesse fundamental passa a ser o fomento ao desenvolvimento humano. Essa perspectiva enfatiza então a preeminência do político, apoiado num projeto social predefinido: a Política, de fato, é o resultado da escolha dos cidadãos no que diz respeito ao interesse comum, a Economia nesse caso apresentando apenas os meios teóricos. Como o mercado tem por objeto satisfazer a demanda, e não a totalidade das necessidades humanas, consequentemente não pode exprimir a totalidade da lógica social, tampouco a complexa rede de valores que coexistem em uma sociedade.

As propostas do Ecodesenvolvimento e do Desenvolvimento Sustentável, que acabamos de examinar, apontam, portanto, insistentemente para a necessidade da preeminência dos valores humanos sobre os valores do lucro, do mercado e do crescimento econômico a qualquer custo. $\mathrm{E}$ esse parece-nos, em última instância, o ponto nevrálgico da questão.

\section{Considerações finais}

Para concluir, podemos dizer que é para uma concepção ampliada da racionalidade científica (no âmbito socioeconômico) que convergem as propostas aqui apresentadas. $\mathrm{Ou}$, pelo menos, para o reconhecimento da necessidade de reestruturação epistemológica e metodológica da economia, o que compromete o ideal de ciência social balizada única e exclusivamente pelo estilo da hard science de cunho positivista. Em outras palavras, isto significa, por um lado, o reconhecimento dos limites estreitos do paradigma científico analítico-reducionista, que tem se mostrado incompatível com os problemas - ainda não resolvidos - de aplicação prática da ciência econômica no campo do planejamento e da gestão. Por outro lado, aponta no sentido de uma abertura progressiva a novos paradigmas científicos.

Nesse sentido, a perspectiva de que existe uma única teoria econômica logicamente estruturada, consistente e que pode ser usada para todos os propósitos precisa ser revista e abandonada em prol da ideia - mais realista - de que existem múltiplas teorias, que são úteis para diferentes objetivos. Ademais, numa democracia, a existência continuada de teorias competidoras, embasadas sobre diferentes perspectivas filosóficas, é altamente salutar tanto em termos puramente teóricos quanto em termos da possibilidade pragmática de resolução dos problemas econômicos do mundo real, dentre os quais ainda se encontra um projeto de desenvolvimento socioeconômico viável para o futuro da humanidade.

Voltando, enfim, à questão inicial, título do trabalho, que deu ensejo a toda a argumentação do texto: "Ecodesenvolvimento, Desenvolvimento Sustentável e Economia Ecológica: em que sentido representam alternativas ao paradigma de desenvolvimento tradicional?" Estas propostas configurar-se-iam, de fato, em alternativas à teoria padrão, uma vez que propõem cisões nos três níveis, interconectados, aos quais fizemos referência no início: epistemológico/ metodológico, teórico e pragmático/político. No plano epistemológico/metodológico, ao introduzir a questão dos valores no âmago do problema do desenvolvimento, elas rompem com um dos primados fundamentais do positivismo lógico, nomeadamente, a normativa de neutralidade axiológica da ciência. No plano teórico, ao redefinir os objetivos da teoria econômica como provisão social, encontramos outra proposta concreta, divergente da alternativa dominante, com todas as implicações daí decorrentes, inclusive aquelas que repercutem no último dos níveis: o pragmático/ político. Deste plano, dado aquilo que agora nos informam os - novos - resultados teóricos, surgem as possibilidades concretas de mudanças de política socioeconômica, em direção a uma autêntica forma de desenvolvimento. 


\section{Referências}

ARISTÓTELES. Política. Brasília: Editora da UnB, 1983.

CAVALCANTI, C. Condicionantes biofísicos da economia e suas implicações quanto à noção do desenvolvimento sustentável. In: ROMEIRO, A. R.; REYDON, B.; LEONARDI, M. L. (Org.): Economia do meio ambiente: teoria, políticas e a gestão de espaços regionais. Campinas: Instituto de Economia da UNICAMP, p. 61-821, 1997.

COASE, R. The Problem of Social Cost. Journal of Law and Economics, v. 3, n. 1, p. 1 -44, 1960.

CONSTANZA, R. (Org.). Ecological economics: the science and management of sustainability. New York: Columbia University Press, 1991.

. Ecological Economics is Post-Autistic. Post-Autistic Economics Review, n. 20, article 2, 2003. Disponível em: $<$ http://www.paecon.net/PAEReview/issue20/Costanza20. htm>. Acesso em: 08/03/2011.

DALY, H. Ecological economics and the ecology of economics. New York: Edward Elgar, 1999.

FAUCHEUX, S.; NOËL, J. F. Economia dos recursos naturais e do meio ambiente. Lisboa: Instituto Piaget, 1995.

GEORGESCU-ROEGEN, N. The Entropy Law and the Economic Process. Harvard University Press, 1971.

HAUWERMEIREN, S. V. Manual de economia ecológica. Santiago: Rosa Moreno, 1998.

JONAS, H. Das Prinzip Verantwortung. Versuch einer Ethik für das technologische Zivilisation. Frankfurt: Harenburg Verlag, 1979.

KEYNES, J. N. The scope and method of political economy. New York: Kelley \& Millman, 1890.

LEFF, H. Epistemologia ambiental. São Paulo: Cortez, 2000.

LACEY, H. Valores e atividade científica. São Paulo: Discurso Editorial, 1998.
Is science value free? Values and scientific understanding. Londres: Routledge, 1999.

LÖWY, M. As aventuras de Karl Marx contra o Barão de Münchausen. São Paulo: Cortez, 1998.

LONGINO, H. Science as social knowledge: values and objectivity in scientific inquiry. New Jersey: Princeton University Press, 1990.

MARTÍNEZ ALIER, J. Da economia ecológica ao ecologismo popular. Blumenau: Editora da FURB, 1998.

MEADOWS, D. et al. The limits to growth. New York: Universe Books, 1972.

MONTIBELLER-FILHO, G. O mito do desenvolvimento sustentável: meio ambiente e custos sociais no moderno sistema produtor de mercadorias. Florianópolis: Editora da UFSC, 2001.

PASSET, R. A ilusão neoliberal. Rio de Janeiro: Record, 2000.

. Un système économique qui détruit l'environnement s'autodétruit. Entretien avec l'economiste René Passet, 2001. Disponível em: <www.diplomatie.gouv.fr/fr/article_imprim. php3?id_article=55878>. Acesso em: 06/03/2011.

ROMEIRO, A. R. Economia ou economia política da sustentabilidade? Texto para Discussão, Campinas: IE/UNICAM, n. 102, p. 1-28, 2001.

SACHS, I. Espaços, tempos e estratégias do desenvolvimento. São Paulo: Vértice, 1981.

. Ecodesenvolvimento: crescer sem destruir. São Paulo: Vértice, 1986.

Estratégias de transição para o século XXI: desenvolvimento e meio ambiente. São Paulo: Studio Nobel/ Fundap, 1993.

WALRAS, L. [1874] Compêndio dos elementos de economia política pura. São Paulo: Abril Cultural, 1986.

Recebido em outubro de 2010. Aceito em março de 2011. Publicado em junho de 2011. 